\title{
CrystEngComm
}

\section{Co-crystallisation of benzoic acid with sodium benzoate: the significance of stoichiometry $\dagger$}

\author{
Christian Butterhof, Wolfgang Milius and Josef Breu*
}

Received 9th February 2012, Accepted 16th March 2012

DOI: $10.1039 / \mathrm{c} 2 \mathrm{ce} 25185 \mathrm{j}$

Currently the synthesis of co-crystals is receiving considerable attention. We studied co-crystallisation of benzoic acid with sodium benzoate in different ratios and with different crystallisation techniques. A crystalline co-crystal, composed of two equivalents of benzoic acid and one equivalent of sodium benzoate $(2 \mathrm{HBz} \cdot 1 \mathrm{NaBz})$ could be identified and structurally characterised. By concomitant coordination of benzoate and benzoic acid the coordination needs of the cation could be satisfied. However, even with a $2: 1$ ratio, an octahedral environment could only be realised by sharing an edge in a dimer. The dimers are connected to one-dimensional tapes which in turn are packed in a distorted hexagonal arrangement. Only with a ratio of two neutral benzoic acid ligands and one benzoate can the coordination requirements of the sodium cation and charge neutrality be assured at the same time.

\section{Introduction}

In the field of crystal engineering, co-crystals have received increasing attention over the last decade. In particular, cocrystals of active pharmaceutical ingredients with small organic molecules are of interest. ${ }^{1-4}$ Physical properties like solubility, dissolution rate, melting point, moisture sorption tendency and compressibility affect the bioavailability, design, manufacturing, and the stability of the resultant dosage form. Despite high interest in co-crystals, the number of reported and characterised co-crystals is rather low $(0.45 \%)$ in comparison with "normal" one-component molecular crystals as pointed out recently by Shan and Zaworotko. ${ }^{3}$ Along with the increasing interest in cocrystallisation a debate arose in the literature regarding the term co-crystal itself. ${ }^{5-8}$ It is now commonly accepted that co-crystals are built up by at least two components which are solid under ambient conditions. Some authors restrict the second component to neutral molecules but others include systems where acid-base reactions occur between the constituents, the so called "salt-cocrystal continuum". 9 Furthermore some ionic co-crystal systems have been characterised. ${ }^{10,11}$

Different approaches have been taken to synthesise cocrystals. A popular route to incorporate both components into a single phase is slow evaporation from solution which contains stoichiometric amounts of the so-called co-crystal formers. Mechanochemical techniques also proved suitable; herein probably the easiest and most frequently applied method is the solvent-drop-grinding technique. ${ }^{12,13} \mathrm{We}$ investigated the

Inorganic Chemistry I, University of Bayreuth, Universitätsstraße 30, 95440 Bayreuth, Germany.E-mail: josef.breu@uni-bayreuth.de; Fax: +49 921 55-2788; Tel: +49 921 55-2530

$\uparrow$ CCDC reference number 865834. For crystallographic data in CIF or other electronic format see DOI: $10.1039 / \mathrm{c} 2 \mathrm{ce} 25185 \mathrm{j}$ co-crystallisation of benzoic acid ( $\mathrm{HBz}$ ) and its corresponding sodium salt $(\mathrm{NaBz})$ in different ratios and with different crystallisation methods. Both species are widely used as preservatives in the food industry. ${ }^{14}$ Interestingly, this is a system where actually the co-crystals are easily accessible while the pure salt, $\mathrm{NaBz}$, does not crystallise well. Therefore, until now the crystal structure of $\mathrm{NaBz}$ could not be solved and refined, despite the rather simple molecular structure. Suitable single crystals for crystal X-ray crystallography could not be obtained. Moreover, the powder diffraction pattern (Fig. 7) is not well resolved and rather featureless, indicating massive structural disorder. Additionally, the $\mathrm{NaBz}$ structure seems to lack three-dimensional translational symmetry as indicated by a featureless PXRD trace of $\mathrm{NaBz}$, which hampers indexing. One reason for the retarded crystallisation behaviour may be related to the simple $1: 1$ stoichiometry. In order to realise the common 6-fold coordination for sodium, the coordination polyhedra would have to be connected in part by shared edges, even if the carboxylate group would act as bidentate ligand. Unfortunately, the large ratio of the volume of the benzoate anion compared with the sodium cation ${ }^{15}$ makes edge sharing difficult. In any case, for $\mathrm{NaBz}$ indexing and hence structure solution proved impossible up to now. A hydrate of $\mathrm{NaBz}$ is also reported but lacks structural characterisation probably for the same reasons. ${ }^{16}$ Another interesting feature of $\mathrm{NaBz}$ is the formation of a smectic liquid crystal phase upon heating above $430{ }^{\circ} \mathrm{C}$. ${ }^{17}$

Contrary to $\mathrm{NaBz}$, the crystal structure of $\mathrm{HBz}$ was determined over 55 years ago. ${ }^{18}$ In this crystal structure hydrogen bonded $\mathrm{HBz}$ dimers can be found. We were interested in the co-crystallisation of both $\mathrm{NaBz}$ and $\mathrm{HBz}$ and particularly in studying the modes by which sodium satisfies its coordination needs and how this changes the hydrogen bonding motif as compared to pure $\mathrm{HBz}$. 


\section{The benzoic acid-sodium benzoate co-crystal system}

In the year 1974 Flammersheim determined the physicochemical properties of the system sodium benzoate-benzoic acid. ${ }^{19}$ Three "complexes" - as he named it at that time - between $\mathrm{NaBz}$ and $\mathrm{HBz}$ were described and characterised by powder X-ray diffraction (PXRD), X-ray single crystal diffraction, infrared (IR) spectroscopy and differential scanning calorimetry (DSC) measurements. The composition of the first "complex" was determined to be $2 \mathrm{HBz} \cdot 1 \mathrm{NaBz}$. It could be crystallised from solution as well as by tribochemical crystallisation methods. For reasons not known, unfortunately, Flammersheim failed to determine the crystal structure, ${ }^{19}$ despite successful indexing $(a=$ 22.29(7) $\AA ; b=14.55(5) \AA ; c=5.89(2) \AA ; \beta=98^{\circ}$, space group to $\left.P 2{ }_{1} / n\right)$. Furthermore, a transition of this " $2: 1$-complex" to a "high temperature modification" was described. This phase transition was claimed to occur upon heating the crystals to $120{ }^{\circ} \mathrm{C}$. Finally, Flammersheim also reported a second "complex" with the composition $1 \mathrm{HBz} \cdot 2 \mathrm{NaBz}$.

In a recent article Brittain described the co-crystallisation of $\mathrm{HBz}$ with $\mathrm{NaBz}$ in a $1: 1$ stoichiometric ratio. ${ }^{20}$ The characterisation of the $1: 1$ stoichiometric product was performed by PXRD, DSC, Fourier-transform infrared (FTIR) and Raman spectroscopy. PXRD, however, was only interpreted in a "qualitative way" by comparing patterns, but no indexing or even structure solution was offered.

\section{Results and discussion}

We investigated the co-crystallisation of $\mathrm{HBz}$ with $\mathrm{NaBz}$ by systematically varying the ratios, crystallisation methods and solvents. Both solvent evaporation crystallisation as well as the popular method of solvent-drop-grinding were performed. We used two different solvents, dry methanol and ethanol-water $(4: 1 / \mathrm{v}: \mathrm{v})$. In the case of methanol the grinding procedure was performed within a glove box under dry nitrogen atmosphere to avoid the formation of possible hydrates (for details see experimental section). Solvent evaporation crystallisation yielded single crystals of good quality with stoichiometry $2 \mathrm{HBz} \cdot 1 \mathrm{NaBz}$.

While solvent-drop-grinding in pure water yielded the same co-crystal, grinding had to be increased significantly to more than $60 \mathrm{~min}$ for complete conversion. Shorter grinding times gave mixtures of $\mathrm{HBz}$ and $\mathrm{NaBz}$ together with the $2 \mathrm{HBz} \cdot 1 \mathrm{NaBz}$ co-crystal. Most likely, the reason for the slower conversion is the poor solubility of $\mathrm{HBz}$ in water $\left(\sim 2.85 \mathrm{~g}^{-1}\right.$ at $\left.20{ }^{\circ} \mathrm{C}\right) .{ }^{21}$ The co-crystal can even be obtained tribochemically without solvent as Flammersheim showed. ${ }^{19}$

\section{Crystal structure of the $2 \mathrm{HBz} \cdot 1 \mathrm{NaBz}$ co-crystal}

A co-crystal of the composition $2 \mathrm{HBz} \cdot 1 \mathrm{NaBz}$ (two neutral benzoic acid molecules per Na-benzoate) is formed in solution as well as by mechanochemical solvent drop grinding (see solventdrop-grinding section). The largest and best single crystals could be grown by slowly evaporating a solution of an ethanol-water (4:1/v : v) mixture, which contained $\mathrm{HBz}$ and $\mathrm{NaBz}$ in a $2: 1$ stoichiometric ratio. Crystal structure solution and refinement turned out to be straightforward. Table 1 shows the crystallographic data for the $2 \mathrm{HBz} \cdot 1 \mathrm{NaBz}$ co-crystal. A comparison of the cell parameters reported by Flammersheim only shows
Table 1 Crystallographic data for the co-crystal $2 \mathrm{HBz} \cdot 1 \mathrm{NaBz}$

\begin{tabular}{|c|c|}
\hline Formula & $\mathrm{C}_{21} \mathrm{H}_{17} \mathrm{NaO}_{6}$ \\
\hline Formula weight & 388.34 \\
\hline$T / \mathrm{K}$ & $293(2)$ \\
\hline Crystal system & Monoclinic \\
\hline Space group & $P 2_{1} / c$ \\
\hline$a / \AA$ & $5.8941(12)$ \\
\hline$b / \AA ̊$ & $14.565(3)$ \\
\hline$c / \AA ̊$ & $22.299(5)$ \\
\hline$\alpha\left({ }^{\circ}\right)$ & 90 \\
\hline$\beta\left(^{\circ}\right)$ & $97.30(3)$ \\
\hline$\gamma\left({ }^{\circ}\right)$ & 90 \\
\hline$V / A^{\circ}$ & $1898.8(7)$ \\
\hline$Z$ & 4 \\
\hline$D_{\mathrm{c}} / \mathrm{g} \mathrm{cm}^{-3}$ & 1.358 \\
\hline$\mu / \mathrm{mm}^{-1}$ & 0.119 \\
\hline$R_{\text {int }}$ & 0.0665 \\
\hline Refln (all/ind) & $3511 / 1867$ \\
\hline$R_{1} / w R_{2}\left(\text { obsd data: } F^{2}>2 \sigma\left(F^{2}\right)\right)^{a}$ & $0.0374 / 0.0840$ \\
\hline$R_{1} / w R_{2}$ (all data) ${ }^{a}$ & $0.0791 / 0.0947$ \\
\hline Largest residual/e $\AA^{-3}$ & 0.172 \\
\hline${ }^{a} R_{l}=\sum\left(\left\|F_{0}|-| F_{c}\right\|\right) / \sum\left|F_{0}\right| ; w h$ & $\left.w\left(F_{0}\right)^{2}\right]^{1 / 2}$ \\
\hline
\end{tabular}

small deviations of the unit cell parameters (see Table 2). Therefore, this structure could be assigned as the same crystallisation product which he described as the "low-temperature complex" of NaBz with HBz.

Description of the crystal structure of $2 \mathrm{HBz} \cdot 1 \mathrm{NaBz}$. The asymmetric unit of the $2 \mathrm{HBz} \cdot 1 \mathrm{NaBz}$ co-crystal is shown in Fig. 1. The packing and its construction from building units is shown in Fig. 2. The structure is composed of one-dimensional tapes (Fig. 2a), which are packed in an approximately hexagonal array. Between these tapes van der Waals forces and one $\pi-$ $\pi$-stacking interaction are the main interaction forces. The $\pi-\pi$ interaction distance between adjacent symmetry equivalent phenyl rings $(\mathrm{C}(16)-\mathrm{C}(21))$ is 3.98(6) $\AA$. A side view on one of the tapes shows that sodium resides, as expected, in a distorted octahedral coordination (see Fig. 2(b), Fig. 3 and Fig. 4). A space filling model (Fig. 2(c)) highlights that the packing in the tapes is dense. No space is available to arrange additional ligands around the Na-moieties. Within the tapes, dimers of edgesharing octahedra become apparent. All carboxylic $(\mathrm{HBz}$, orange) and carboxylate ( $\mathrm{NaBz}, \mathrm{red})$ groups act as monodentate ligands in respect to a given dimer. Carboxylate groups of two benzoate anions are involved in the shared edge (Fig. 3).

Of the three $\mathrm{HBz}$ molecules in an octahedron, one is coordinated with its hydroxyl $(\mathrm{O}(2))$, the other two via their carbonyl oxygens $(\mathrm{O}(1), \mathrm{O}(5))$. Eight out of ten ligands involved in the coordination sphere of a dimer connect the dimer in both

Table 2 Comparison of the cell parameters with the published values

\begin{tabular}{lll}
\hline & This work & Flammersheim $^{19}$ \\
\hline Crystal system & Monoclinic & Monoclinic \\
Space group & $P 2_{1} / c$ & $P 2_{1} / n$ \\
$a / \AA$ & $5.8941(12)$ & $22.29(7)$ \\
$b / \AA$ & $14.565(3)$ & $14.55(5)$ \\
$c / \AA$ & $22.299(5)$ & $5.89(2)$ \\
$\alpha\left({ }^{\circ}\right)$ & 90 & 90 \\
$\beta\left({ }^{\circ}\right)$ & $97.30(3)$ & 98 \\
$\gamma\left({ }^{\circ}\right)$ & 90 & 90
\end{tabular}




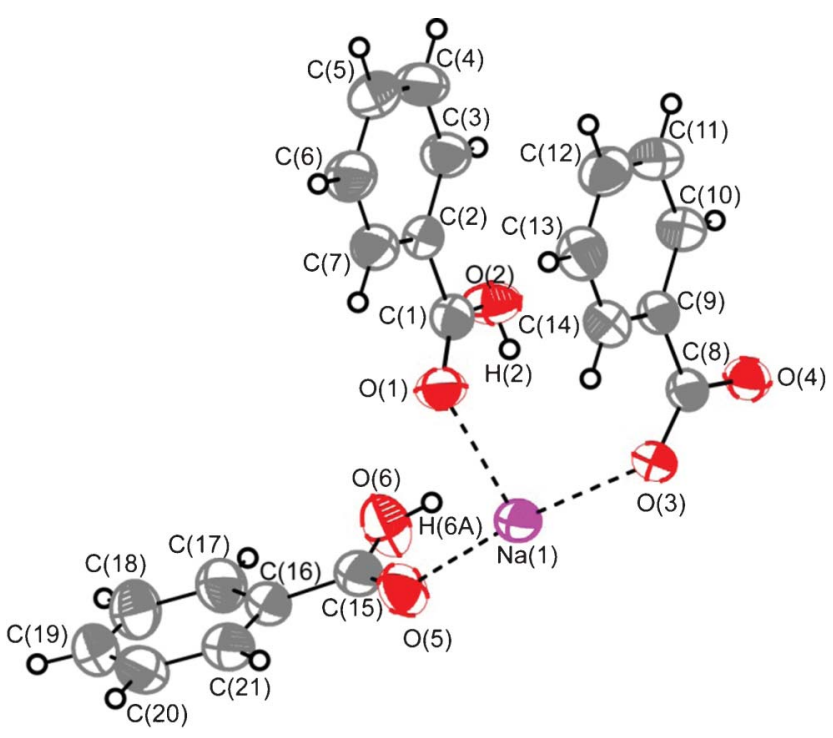

Fig. 1 ORTEP plot and the crystallographic numbering scheme of the asymmetric unit for the co-crystal $2 \mathrm{HBz} \cdot 1 \mathrm{NaBz}$. Displacement ellipsoids are drawn at the $50 \%$ probability level.

directions to a one-dimensional tape via bridging carboxylic/ carboxylate groups (Fig. 4). The two remaining carboxylic ligands realise a $\mathrm{H}$-bond between $\mathrm{O}(6)$ and $\mathrm{O}(4)$ (Fig. 4 and Table 3). This inter-dimer bond reinforces the dimer. A second intra-dimer $\mathrm{H}$-bonding between $\mathrm{O}(2)$ and $\mathrm{O}(4)$ (Fig. 4 and Table 3) contributes to the formation of the tapes.

Adjacent phenyl groups within the tapes are involved in shifted $\pi$-stacks (Fig. 2(c)), (interaction between phenyl rings of $(\mathrm{C}(2)-\mathrm{C}(7))$ and $(\mathrm{C}(9)-\mathrm{C}(14)))$. The $\pi-\pi$ stacking distance is $3.87(3) \AA$

\section{Solvent-drop-grinding}

With a ratio of $2: 1$, a phase pure material was obtained as indicated by the PXRD trace (Fig. 5). In the presence of both solvents, dry methanol and ethanol-water $(4: 1 / \mathrm{v}: \mathrm{v})$, cocrystals of $2 \mathrm{HBz} \cdot 1 \mathrm{NaBz}$ were obtained as a pure phase for both solvent evaporation and solvent drop grinding.

In the literature co-crystals of ratios diverging from $2: 1$ have been reported, e.g. $1: 1$. Such $\mathrm{NaBz}$ rich compositions would only be able to satisfy the coordination needs of sodium if the degree of condensation of octahedra could increase beyond the level of edge sharing dimers observed in $2 \mathrm{HBz} \cdot 1 \mathrm{NaBz}$. Since the packing of ligands around the sodium cation is, however, already dense with $2 \mathrm{HBz} \cdot 1 \mathrm{NaBz}$ (Fig. 2(c)), it might appear that a periodic, crystalline molecular packing of the ligands might be difficult to realise. Nevertheless we explored both $\mathrm{NaBz}$ rich and poor stoichiometries by solvent-drop-grinding crystallisations. The experimental details are given in the experimental section.

$\mathrm{NaBz}$ poor stoichiometries: $\mathrm{HBz}: \mathrm{NaBz}=3: 1$. Independently of the two solvents applied, dry methanol and ethanol-water $(4: 1 / \mathrm{v}: \mathrm{v})$, a mixture of the co-crystal $2 \mathrm{HBz} \cdot 1 \mathrm{NaBz}$ and crystalline HBz was obtained. The PXRD trace observed is a simple overlay (Fig. 6).

Despite the massive overlap, free $\mathrm{HBz}$ can be clearly identified by a few unique reflections, the most prominent appeared at

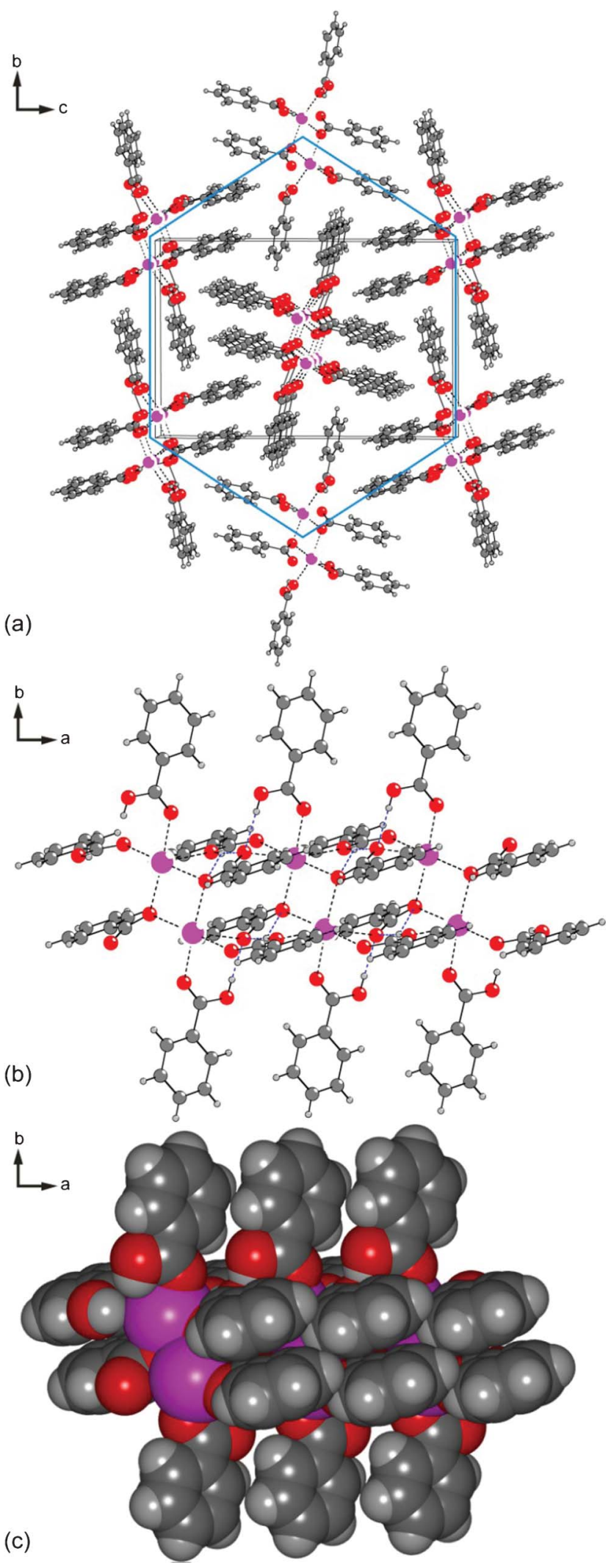

Fig. 2 Molecular packing in the $2 \mathrm{HBz} \cdot 1 \mathrm{NaBz}$ co-crystal of $\mathrm{HBz}$ with $\mathrm{NaBz}$. (a) Approximately hexagonal packing of one-dimensional tapes along the $a$-axis. (b) Side view on one of the tapes. Coordination bonds are black and hydrogen bonds blue dashed. (c) Space filling model of one tape highlighting the dense packing around sodium. 


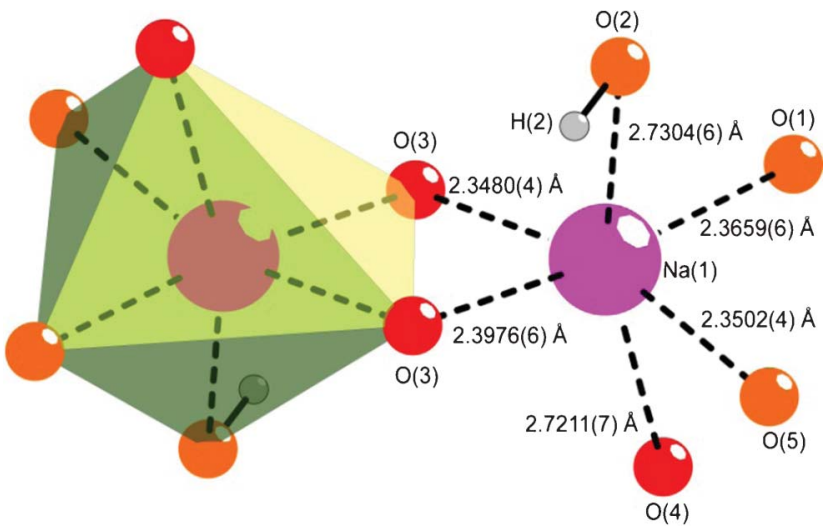

Fig. 3 Coordination sphere of sodium in the co-crystal $2 \mathrm{HBz} \cdot 1 \mathrm{NaBz}$. The $\mathrm{Na}-\mathrm{O}$ distances show the strongly distorted octahedral coordination. Oxygen atoms belonging to carboxylic groups $(\mathrm{HBz})$ are in orange, while oxygen atoms belonging to carboxylate groups $(\mathrm{NaBz})$ are in red.

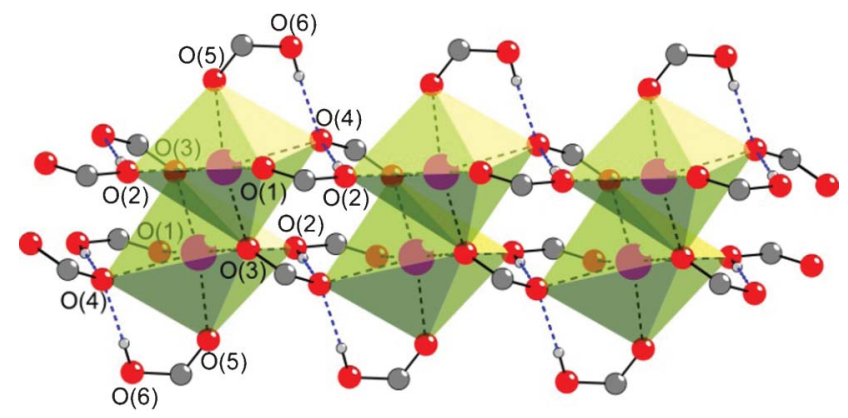

Fig. 4 Overview of the connection of the edge sharing octahedron pairs. The exact connection is described in the text. For clarity, phenyl rings of $\mathrm{HBz}$ and $\mathrm{NaBz}$ are not shown. Hydrogen bonds are blue dashed.

Table 3 Summary of intermolecular interactions (D-H $\left.\cdots A ; \AA, \quad{ }^{\circ}\right)$ operating in the crystal structure of $2 \mathrm{HBz} \cdot 1 \mathrm{NaBz}$

\begin{tabular}{lllllll}
\hline $\mathrm{D}$ & $\mathrm{H}$ & $\mathrm{A}$ & $\mathrm{H} \cdots \mathrm{A} / \AA$ & $\mathrm{D} \cdots \mathrm{A} / \AA$ & $\Varangle(\mathrm{DHA}) /^{\circ}$ & Symmetry operation \\
\hline $\mathrm{O}(2)$ & $\mathrm{H}(2)$ & $\mathrm{O}(4)$ & 1.77 & $2.5840(19)$ & 174.7 & $-\mathrm{x},-\mathrm{y}+1,-\mathrm{z}+1$ \\
$\mathrm{O}(2)$ & $\mathrm{H}(2)$ & $\mathrm{O}(3)$ & 2.59 & $3.147(2)$ & 126.0 & $-\mathrm{x},-\mathrm{y}+1,-\mathrm{z}+1$ \\
$\mathrm{O}(6)$ & $\mathrm{H}(6 \mathrm{~A})$ & $\mathrm{O}(4)$ & 1.86 & $2.683(2)$ & 176.6 & $-\mathrm{x},-\mathrm{y}+1,-\mathrm{z}+1$ \\
\hline
\end{tabular}

$27.79^{\circ} 2 \Theta,(3.21 \AA)$. All reflections are sharp and can be indexed by either $2 \mathrm{HBz} \cdot 1 \mathrm{NaBz}$ or crystalline $\mathrm{HBz}$.

$\mathrm{NaBz}$ rich stoichiometries: $\mathrm{HBz}: \mathrm{NaBz}=1: 1$ to $1: 5$. $\mathrm{Up}$ to a stoichiometric ratio of $1: 3$, reflections of the co-crystal $2 \mathrm{HBz} \cdot 1$ $\mathrm{NaBz}$ are clearly visible. Additional week reflections (e.g. $3.75^{\circ}$ $2 \Theta,(23.55 \AA) ; 6.15^{\circ} 2 \Theta,(14.36 \AA) ; 16.68^{\circ} 2 \Theta,(5.31 \AA) ; 18.45^{\circ}$ $2 \Theta,(4.80 \AA) ; 22.80^{\circ} 2 \Theta,(3.90 \AA)$, asterisks in Fig. 7) appear which are most intense at a ratio of $1: 2$. Despite considerable effort, we failed to index these additional reflections.

The pattern of these additional reflections differs from the PXRD trace of $\mathrm{NaBz}$ prepared in a similar way, however, the most intense peak is identical. Since at a ratio of $1: 2,2 \mathrm{HBz} \cdot 1$ $\mathrm{NaBz}$ is still clearly present, the residual material must have a composition which is even richer in $\mathrm{NaBz}$ than $1: 2$ and it would be expected that the intensity of these additional reflections should further increase with ratios lower than $1: 2$. However,

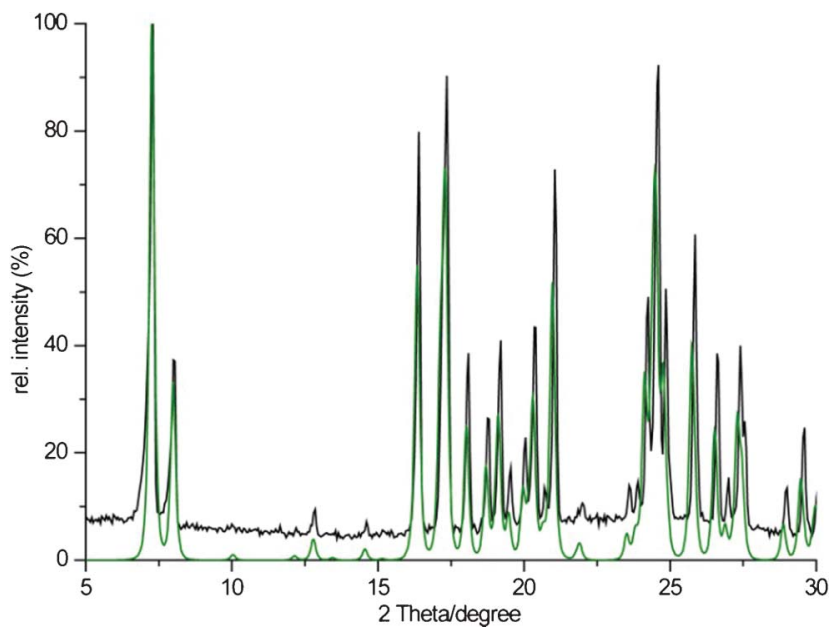

Fig. 5 Powder diffraction pattern of the co-crystal $2 \mathrm{HBz} \cdot 1 \mathrm{NaBz}$. The green trace displays the simulated single crystal diffraction pattern as a reference (calculated with FWHM $=0.2^{\circ} 2$ Theta).

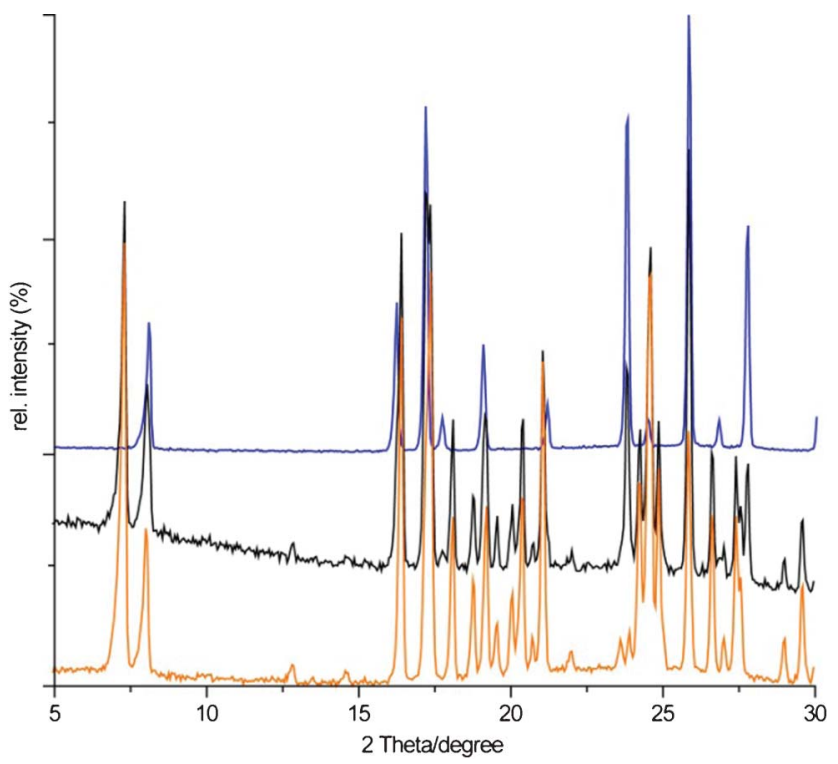

Fig. 6 PXRD traces of products crystallised by solvent drop grinding from ethanol-water $(4: 1 / \mathrm{v}: \mathrm{v})$ (blue trace: $\mathrm{HBz}$ drop grinded with ethanol-water $(4: 1 / \mathrm{v}: \mathrm{v})$, black trace: $\mathrm{HBz}: \mathrm{NaBz}=3: 1$, orange trace: $\mathrm{HBz}: \mathrm{NaBz}=2: 1)$.

contrary to this expectation, the intensity of the additional reflections instead decreases with further increasing $\mathrm{NaBz}$ content. The PXRD trace of the $1: 3$ ratio is already rather featureless, with a further decreasing ratio the pattern gradually blends into the pure $\mathrm{NaBz}$ trace in a kind of metamorphic transition. Another interesting feature is the gradual shift of the first reflection at $3.75^{\circ} 2 \Theta$ to higher d-values with decreasing $\mathrm{HBz}: \mathrm{NaBz}$ ratio. Such gradual shifts are well known for randomly interstratified intercalation compounds. Furthermore, the featureless appearance of the PXRD trace of $\mathrm{NaBz}$, which hampers indexing, might also be due to disorder.

Although the existence of a crystalline phase with a ratio smaller than $2: 1$ can not definitely be ruled out at this stage, the observations described most likely point to a semicrystalline 


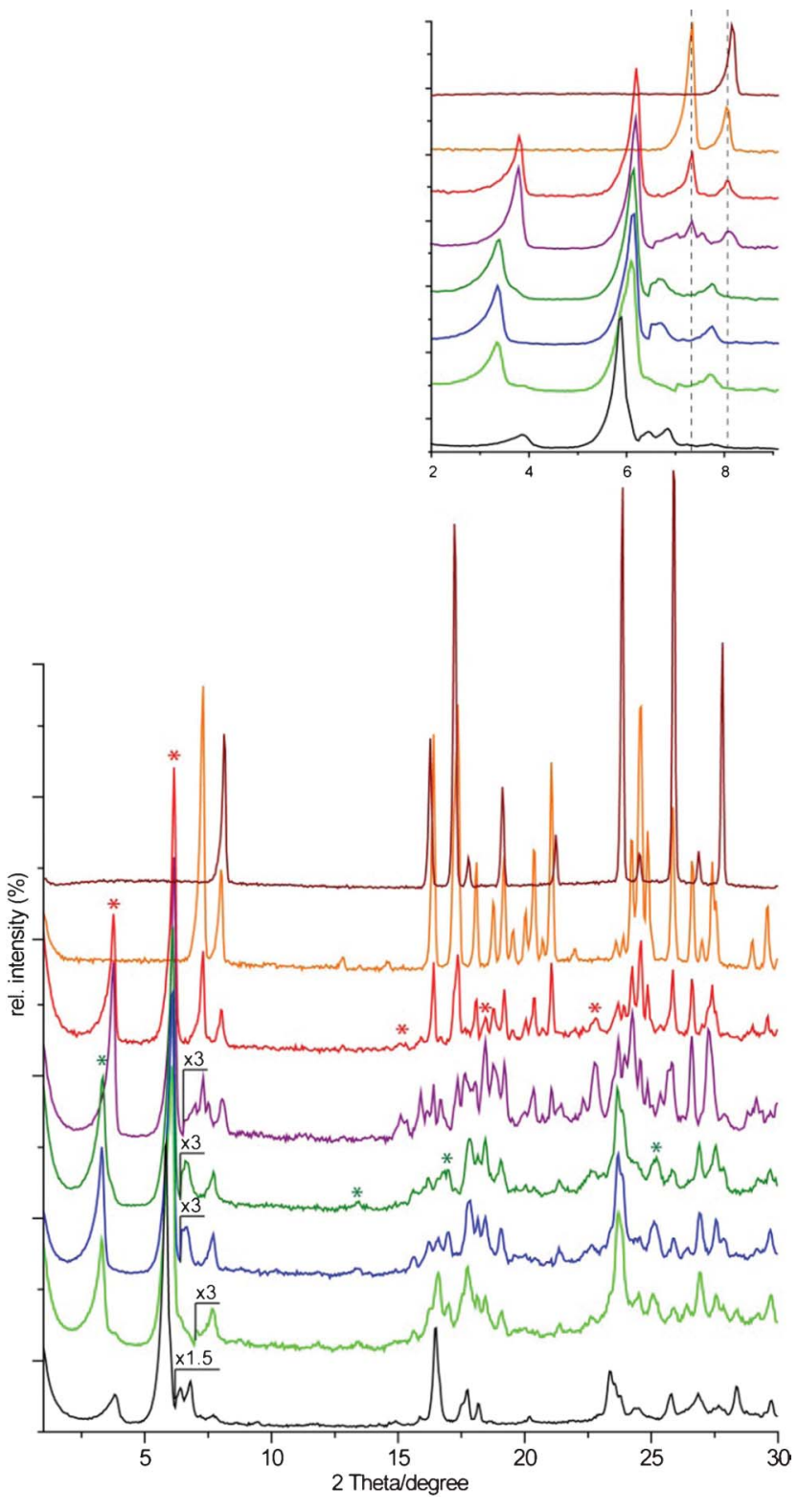

Fig. 7 PXRD traces of products crystallised by solvent drop grinding from ethanol-water $(4: 1 / \mathrm{v}: \mathrm{v})$. (brown trace: pure $\mathrm{HBz}$, orange trace: $\mathrm{HBz}: \mathrm{NaBz}=2: 1$, red trace: $\mathrm{HBz}: \mathrm{NaBz}=1: 1$, purple trace: $\mathrm{HBz}: \mathrm{NaBz}=1: 2$, dark green trace: $\mathrm{HBz}: \mathrm{NaBz}=1: 3$, blue trace: $\mathrm{HBz}: \mathrm{NaBz}=1: 4$, light green trace: $\mathrm{HBz}: \mathrm{NaBz}=1: 5$, black trace: pure $\mathrm{NaBz}$ ). The inset shows a magnification of the range from $2^{\circ} 2 \Theta$ to $9^{\circ} 2 \Theta$. The disappearance of peaks related to the $2 \mathrm{HBz} \cdot 1 \mathrm{NaBz}$ cocrystal with decreasing $\mathrm{HBz}$ : NaBz ratio can be monitored.

material. We propose that $\mathrm{NaBz}$ as obtained by drop grinding is composed of low dimensional building units which are packed in a disordered way and which might be capable of intercalating various (non-stoichiometric) amounts of neutral HBz molecules.

\section{Experimental}

$\mathrm{NaBz}$ (purity $\geqslant 99.0 \%$ ) and $\mathrm{HBz}$ (purity $>99.5 \%$ ) were purchased from AppliChem. Ethanol was sourced from VWR (BDH Prolabo) and methanol $\left(\mathrm{H}_{2} \mathrm{O}<0.01 \%\right)$ from SigmaAldrich. Methanol was dried over molecular sieves, while all other chemicals and solvents were used without further purification. Distilled water was used. PXRD traces were recorded using a STOE STADI $\mathrm{P}\left(\mathrm{Cu}_{\mathrm{K} \alpha 1}\right.$ radiation, transmission geometry) diffractometer. The samples were filled in capillaries (diameter $0.5 \mathrm{~mm}$ ). Single-crystal X-ray diffraction data were collected using a STOE IPDS I instrument $\left(293 \mathrm{~K}, \mathrm{Mo}_{\mathrm{K} \alpha}\right.$ radiation). Selected crystallographic data are listed in Table 1. The crystal structure was solved and refined using SHELXTL 5.1 (Bruker AXS). All figures were drawn with the DIAMOND programme.

\section{Crystallisation from solution}

Single crystals were obtained from a supersaturated solution of $4.885 \mathrm{~g}$ (40.00 mmol) $\mathrm{HBz}$ and $2.882 \mathrm{~g}(20.00 \mathrm{mmol}) \mathrm{NaBz}$ in $35 \mathrm{ml}$ ethanol-water mixture $(4: 1 / \mathrm{v}: \mathrm{v})$. This mixture was heated up to $50{ }^{\circ} \mathrm{C}$, until all starting material was dissolved. Afterwards the solution was cooled very slowly (over $3 \mathrm{~h}$ ) to room temperature. Then the solution was left at room temperature. After three days spicular, colourless crystals could be collected. These were filtered off the mother liquid and dried at room temperature. All other experiments were performed in the same way by using different ratios of $\mathrm{HBz}$ and $\mathrm{NaBz}(1: 1$; $2: 1 ; 1: 2)$ and by using the ethanol-water mixture $(4: 1 / \mathrm{v}: \mathrm{v})$ or methanol as solvent.

\section{Tribochemical crystallisation}

The popular method of solvent-drop-grinding with a typical hand-mortar was applied. Different ratios of $\mathrm{HBz}$ and $\mathrm{NaBz}$ $(3: 1 ; 2: 1 ; 1: 1 ; 1: 2 ; 1: 3 ; 1: 4 ; 1: 5)$ (total quantities: $1500 \mathrm{mg}$ ) were wetted with the corresponding solvent (ethanolwater mixture ( $4: 1 / \mathrm{v}: \mathrm{v})$ or methanol) and then ground to dryness. In the case of methanol the grinding procedure was performed within a dry nitrogen atmosphere. The capillaries for PXRD were filled within a glove box to avoid contact with air humidity.

\section{Conclusions}

Co-crystallisation experiments of $\mathrm{HBz}$ with its corresponding sodium salt were performed with the help of different crystallisation techniques. The ionic co-crystal $2 \mathrm{HBz} \cdot 1 \mathrm{NaBz}$ was crystallised by different methods (tribochemical and solution) and its crystal structure was determined by single-crystal structure refinement. By concomitant coordination of benzoate and $\mathrm{HBz}$, the coordination needs of the cation could be satisfied. However, even with a $2: 1$ ratio, an octahedral environment could only be realised by sharing an edge in a dimer. The dimers are connected to one-dimensional tapes which in turn are packed in a distorted hexagonal arrangement.

\section{References}

1 O. Almarsson and M. J. Zaworotko, Chem. Commun., 2004, 1889-1896.

2 Polymorphism in the Pharmaceutical Industry, R. Hilfiker, WileyVCH Verlag, Weinheim, Germany, 2006.

3 N. Shan and M. J. Zaworotko, Drug Discovery Today, 2008, 13, 440-446.

4 P. Vishweshwar, J. A. McMahon, J. A. Bis and M. J. Zaworotko, J. Pharm. Sci., 2006, 95, 499-516. 
5 J. Zukerman-Schpector and E. R. T. Tiekink, Z. Kristallogr., 2008, 223, 233-234.

6 J. D. Dunitz, CrystEngComm, 2003, 5, 506.

7 G. R. Desiraju, CrystEngComm, 2003, 5, 466-467.

8 A. D. Bond, CrystEngComm, 2007, 9, 833-834.

9 S. L. Childs, G. P. Stahly and A. Park, Mol. Pharmaceutics, 2007, 4, 323-338.

10 D. Braga, F. Grepioni, L. Maini, S. Prosperi, R. Gobetto and M. R. Chierotti, Chem. Commun., 2010, 46, 7715-7717.

11 S. L. Childs, L. J. Chyall, J. T. Dunlap, V. N. Smolenskaya, B. C. Stahly and G. P. Stahly, J. Am. Chem. Soc., 2004, 126, 13335-13342.

12 A. V. Trask, W. D. S. Motherwell and W. Jones, Chem. Commun., 2004, 890-891.

13 A. V. Trask, D. A. Haynes, W. D. S. Motherwell and W. Jones, Chem. Commun., 2006, 51-53.
14 E. Luck, Zbl. Bakt. Mik. Hyg. I. C., 1985, 180, 311-318.

15 A. L. Rohl and D. M. Mingos, J. Chem. Soc., Dalton Trans., 1992, 3541-3552.

16 K. S. Howard, Z. K. Nagy, B. Saha, A. L. Robertson and G. Steele, Org. Process Res. Dev., 2009, 13, 590-597.

17 R. Van Deun, J. Ramaekers, P. Nockemann, K. Van Hecke, L. Van Meervelt and K. Binnemans, Eur. J. Inorg. Chem., 2005, 563-571.

18 G. A. Sim, J. M. Robertson and T. H. Goodwin, Acta Crystallogr., $1955,8,157-164$

19 H. J. Flammersheim, Krist. Tech., 1974, 9, 299-311.

20 H. G. Brittain, Cryst. Growth Des., 2010, 10, 1990-2003.

21 Handbook of aqueous solubility data, S. H. Yalkowsky, Boca Raton, London New York Washington, D.C., 2012. 